\title{
Provincial Designer Design: A Creative Mix of Hard Restrictions and Soft Visions of an Information Systems Educational Program
}

\author{
Darek Haftor ${ }^{1}$, Stig C Holmberg ${ }^{2}$, Ulrica Löfstedt ${ }^{2}$, \\ Christina Amcoff Nyström², and Lena-Maria Öberg ${ }^{2}$ \\ ${ }^{1}$ School of Business, Stockholm University, 10691 Stockholm, Sweden \\ dhefek.su.se \\ ${ }^{2}$ ITM / Informatics, Mid Sweden University, 83125 Östersund, Sweden \\ \{stig.holmberg, ulrica.lofstedt, christina.amcoff, \\ lena-maria.oberg\} @miun.se
}

\begin{abstract}
This paper presents a brief historical account of the unorthodox design of an educational program for information systems development. The design and development of this program was initiated in 1977 at the University College of Östersund, today the Mid Sweden University. The presented account provides a description of the somewhat unusual context of this initiative, which was regarded as a weakness by conventional standards, but became an opportunity in this particular situation. The intellectual inspirations and sources for the design of this program are characterized and followed by a presentation of the very content and operating mode of the educational program. The final part presents the various outcomes that the program gave rise to, in terms of students' professional careers observed.
\end{abstract}

Keywords: Historical reflections, informatics, systems design, systems sciences.

\section{Introduction}

Due to a misplaced " $\mathrm{X}$ " in the governmental distribution matrix for higher education, a study program in Information Systems Development (ISD) ${ }^{1}$ was started in Östersund, Sweden, at its University College, in 1977 (hereafter the Östersundprogram). Despite such an accidental start in a rural milieu far from the epicenter of Nordic computing, it fostered a systems culture and nearly one thousand students have successfully completed their ISD studies. The purpose of this paper is to provide a short historical account of this unorthodox educational program. Its challenging context is first briefly characterized and then followed by an account of the key sources of intellectual inspiration. The mode of operation and the design of the very content are described thereafter. This account concludes with some highlights of the outcomes generated by this unusual educational program for information system development.

\footnotetext{
1 “Systemvetenskapliga linjen" in Swedish.
} 


\section{The Context}

The Östersund-program was established and developed under very specific conditions. Consequently, there was no history and no tradition in computing or computer-related education at hand; neither the host university nor the local industry showed any particular interest or engagement in the activity. Furthermore, resources were very limited and the research activity was simply low. While these factors at first glance were regarded as negative for the development of a successful educational program, they actually turned out to constitute a positive foundation for the development of the Östersund-program.

The developmental milieu became very energetic and open to inputs from all over the world. As there were few external restrictions imposed, the faculty teaching this program had almost unlimited freedom regarding experimentation and creative design approaches. Not being bound to expensive hard- and software also made it easy to follow the rapid development within the various Information and Communication Technologies (ICT). Due to the limited initial research opportunities, the educational program itself became the main research and development laboratory and target [1].

\section{The Inspiration}

Although the igniting spark came from Uppsala University, the design of the Östersund program was initially mainly inspired by the research and teaching activities conducted at the Royal Institute of Technology (KTH), Stockholm. The new Department for Information Processing (called 'Administrative Data Processing', or 'ADB' in Swedish), led by Professor B. Langefors [2], constituted a significant part of that initial input; however, major influences also came from several other departments at KTH.

Over the years, Professor K. Ivanov [3] at Umeå University and Professor K. Samuelson at KTH [4] in Stockholm have had a distant yet important influence on the developmental activities in Östersund. Quite soon, however, Östersund became part of an international network of researchers with links to academic nodes such as $\mathrm{St}$ Gallen [5], Fribourg [6], Washington [7], Hull [8], and San Fransisco [9, 10] among others. We only realized later that the extensive international networking and cooperation had become somewhat of a hindrance to greater national and Scandinavian cooperation. With regard to technological development, the key inspiration came from Sommerville [11] and Wirth [12] and, to some extent, from professional organizations such as the IEEE Computer Society [13] and the ACM [14].

\section{The Operation}

The operation of the program can be characterized by both conservation and change. The vision to support human activity systems [9] with the best information systems 
possible remained unchanged for the whole period. The ways and tools for reaching that goal, on the other hand, were under constant change. That change was driven by a program improvement system (IPS) which, in fact, was an expanded and completed course evaluation system. Nearly all the stakeholders, that is, the lecturers, students, external experts, and industry representatives were engaged in IPS. In that respect, we came close to Banathy's [17] vision of a third generation of design methods. All possible information was gathered here during the year and people used it as input to annual design seminars. In those, the program was designed with the help of Ackoff's [16] idealized design.

This cycle of operation-design ran very well for several years, but was eventually overwhelmed by changes in the host organization. Hence, the freedom and energy gradually disappeared and the responsibility was removed from the lecturing faculty.

\section{The Design}

The Östersund program successively evolved over the years. Its idealized design [16] was finally grounded on the following cornerstones.

\subsection{The Program Focus}

Contrary to conventional ISD educational programs [18], the Östersund program had the problem-domain as its main area of attention (Fig. 1). In that respect, the program followed the user-orientation already advocated by Langefors [2]. This also made the program more process-oriented and thus less content-oriented, compared to the more conventional arrangements [18]. In that respect, the program honored Popper's searchlight knowledge paradigm [20].

Furthermore, on the basis of Beer's [19] dictum that techniques and tools should not be regarded as a challenge as long as one knows what one wants to do, very little explicit time was assigned to the study of different technologies, techniques, and tools along the solution arsenal, in Fig. 1 (as represented by the vertical axis). Far from all the students agreed on this point, but we still hold to the assumption that a relevant amount of technical meta-knowledge is the best approach for the optimal application of a rapidly moving technology front.

The design focus in Fig.1 represents the core program goal of forming skills to solve human information and communication problems, by applying the best available techniques in an ingenious way. Very soon, however, we discovered that information systems design was just a special case of a more generic design science. Hence, Simon [15], Warfield [7], Ackoff [16], and Banathy [17] became the main sources of inspiration for our design courses.

Thanks to Samuelson [4], the program was, from the beginning, embedded in a systemic framework. Hence, the term "system informatics" (systeminformatik) was coined as a label. Ulrich [6] helped us here not to overdo the systems approach. 


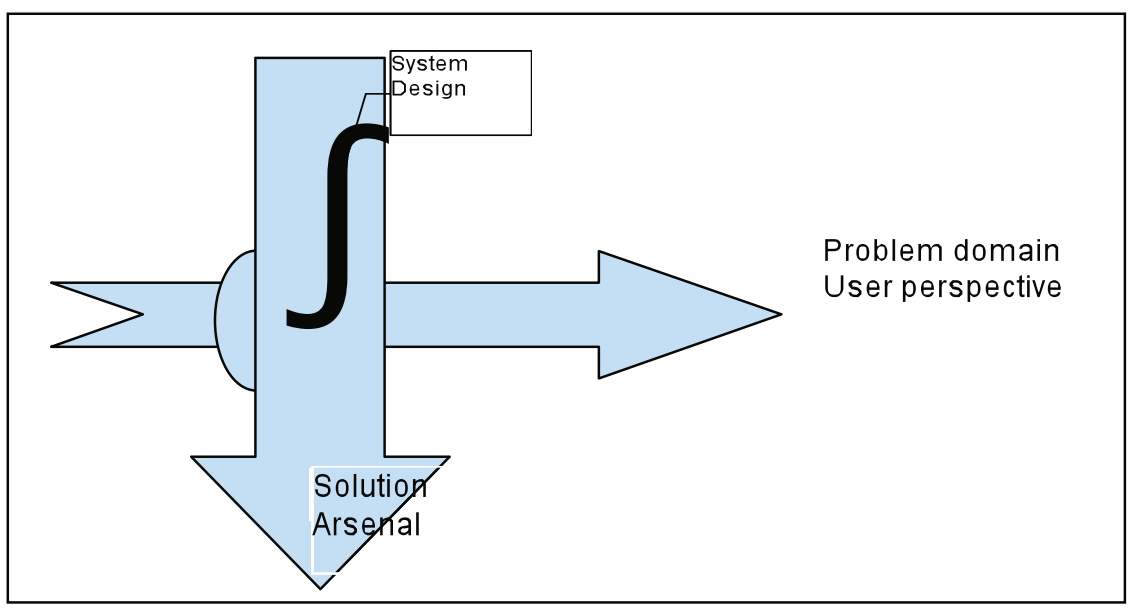

Fig. 1. The figure illustrates two dimensions of the conception of the Östersund-program; the Problem-domain axis constituted the main focus of attention for the students, i.e., how to define relevant problems and opportunities; while the Solution-arsenal axis constituted the tool-box and meta-learning capabilities offered the students to handle problem solutions in a successful manner

\subsection{The Expanding System Complexity}

One core principle that guided the design and execution of the Östersund program was to increase successively the complexity of the systems studied by the students [21]; from deterministic and foreseeable systems, through teleological and living systems [24], to the social and very complex systems. From the very start, a process for the effectiveness of individual study was provided to the students, which proceeded from the computer and program systems, the information and workflow systems, and concluded with organizational and inter-organizational systems. In subsequent semesters, very complex real-world systems were studied and re-designed according to viable system design principles [19].

\subsection{Creativity and Problem Solving}

One should characterize systems development and problem solving by a high degree of creativity. On this point, different innovative activities such as "six-thinking-hats" and "the devil's advocate" were applied, in order to minimize the limitations of undesired thinking [23]. Brainstorming, brain-drawing, and brain-writing techniques were also used to support the students' lateral thinking and idea generation.

The studies were further characterized by a high degree of problem solving, due to the assumption that students can solve any problem if they are given the chance [25]. Hence, the practical assignments were normally not "tested in advance" and the teaching team did not have the "right" solution.

\subsection{The Learning Approach}

"Learning by doing" is a stimulating way of learning in line with Schön's [22] "learning by experience and reflections." In the program assignments termed "close to reality," the students appreciated the assignments, which were often executed 
together with different stakeholders. The ability to communicate with "real" stakeholders, presenting different ideas and negotiating proposed solutions, was identified as an essential skill for the future developers of information systems. Hence, in this respect, the program conformed with Ackoff's [25] position that case studies and fictive descriptions can never work as well as authentic cases.

According to Warfield [7], the working environment is an important component in the design result. Therefore, the program abandoned the computer-lab concept and instead created environments that resembled normal working places as much as possible. In this, the students were free, within certain limits, to equip and use their theme labs according to their own liking.

\subsection{The Theme Semesters and the Course Teams}

In order to avoid fractionating in allowing the study of complex real-world problems, courses of a certain length were found necessary. Hence, the idea of educational "theme semesters" was born. The program mainly comprised the following semesters: (a) personal effectiveness in academic studies, (b) computer systems, (c) information systems, (d) organizational systems, and (e) knowledge creating systems.

Furthermore, in order to cover all the aspects of long and wide ranging courses and to give students the best possible study conditions, the concept of "course teams" was initiated. A course team was a group of faculty members, responsible for a theme semester; it had to collaborate closely in order to run the given semester. A guiding principle for the constitution of a course team was to provide it with comprehensive coverage and to expose students to a variety of complementary knowledge and facilitation. A model building on Warfield's [7] Sigma Five was developed as a guide for the teams' working mode.

\subsection{The Inter-course Interaction}

"You always work for some client." This expression can characterize a key quality of the Östersund program, namely, that the various semesters had to interact with each other. The idea of utilizing results generated by student groups in one theme semester as inputs to other student groups in another theme semester included three theme semesters. In this case, "the Realization of Information Systems" was guided by the systems requirements from "the Design of Information Systems" which, in turn, was guided by the systems requirements obtained from the "Strategy and Management Organizations," as shown in Fig. 2. Hence, designs from semester five were given to semester three for realization, while organizational strategies and more local management plans, formulated within semester six, were given to semester five students for the design of an appropriate information system. All this gave rise to valuable communication and negotiation exercises, including conflict resolution and management!

\subsection{The Meta Learning Capability}

Within a fast moving area such as ICT, the ability to learn during the whole professional period is judged more important than what you have learned during your 


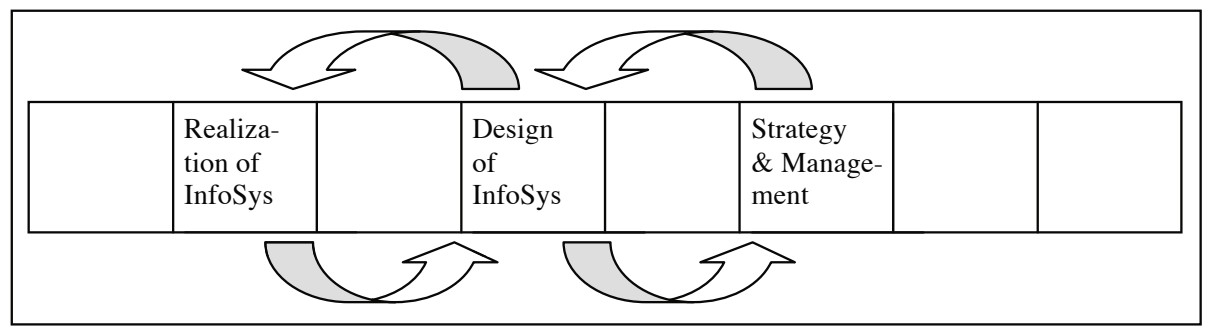

Fig. 2. The figure illustrates a key feature of the Östersund program: outcomes generated by students from one theme-semester constituted the inputs (i.e. systems requirements) for students in another theme-semester

undergraduate studies. Hence, in accordance with Popper [20] and in an effort to foster desirable meta-learning skills, the program was filled with the following metalearning moments:

- bachelor students had to make an independent compilation and assessment of current relevant research results;

- bachelor students had to make an independent implementation of a new research result into an actual professional activity (bachelor thesis);

- master students had to plan and implement their own work for a full semester, in accordance with given outcome targets, which was to develop a new idea or research result into a viable business or organization;

- master students had to independently plan and realize a minor research project, the result of which had to be reported in the form of a scientific paper.

Beside the fact that most students found these tasks particularly challenging and stimulating, the results were often surprisingly good. For example, several students had their paper presented at international academic conferences and some succeeded in publishing their paper in international scientific journals, while still others received best paper awards. This brings us to the last part of this historical account, some of the outcomes produced by the Östersund program.

\section{The Outcome}

Plans and design may be one thing, while results and outcomes often turn out to be something quite different. In order to provide a snapshot of some of the results generated by the Östersund program, four former students were asked to submit testimonials with regard to what they judged to be the most significant aspect in the Östersund program. A summary of their testimonials follows.

\subsection{The IS Professional Perspective}

The Östersund program aimed to prepare the future "systems professionals" for a successful intervention of human, industrial, and social affairs, by means of 
embedding ICT-artifacts into such contexts. Three key capabilities that the program provided students with, which aim to fulfill this ambitious target, are discussed here.

The first capability is decomposing the social and technological complexity by providing skills that conceptualize any intervention situation in terms of three layers of the intervened systems. The first of these three layers is the ICT-artifact layer, with all its techno-aspects such as programming, configurations, and testing, among others. This capability was provided to the students by means of education and training that centered on the construction of software and database systems and enabled the future systems professionals to understand the workings of the various ICT. The second layer, the workflow layer, addressed the understanding of the work processes, in and between organizations, which are enabled by ICT-artifacts. This conceptualization was provided to the students by means of education and training that centered on the analysis and design of various workflows and the identification of the requirements of the supporting ICT-artifacts. With this capability, the future professional was able to understand the logic of human activity systems, its challenges, and the potential value that modern ICT-systems may or may not contribute to the workflows. The third layer, the organizational layer, addressed a whole organization, or a set of such, and was comprised of various interacting workflows, including the different resources (technological, human, and financial), as well as their regulatory and intentional properties.

This triplex, artifact-workflow-organization, provided the future professionals with "intellectual spectacles" that enabled successful conceptualizations, interpretations, and designs, as well as the management of the various professional challenges at hand.

The second capability of the systems professional focused on the articulation and handling of the gap between theoretical-knowledge and professional-practice. All professions have their hidden, tacit, and professional knowledge that cannot be reduced and communicated via standard textbooks. Hence, by exposing the future systems professional to a well-designed mix of theoretical bodies - e.g., software engineering theory or organizational behavior - and then a stepwise real-life application of these, followed by critical evaluation, the capability of bridging the gap between the abstract and the concrete was established!

The third capability addressed the distinction and opposition between analysis and design. The ability to analyze, understood as comprehending what exists by taking it apart (at least conceptually), is important and well provided to most of us by our western cultural tradition. However, even the best analysis capability cannot help us with the creation of a new and wanted reality. The latter requires the design capability, often allocated to "the strange artists"! By providing an exposition for the theoretical foundations - such as the systems sciences - and the practical hands-on doings of analysis and design, the ability to master these two mental and operational approaches, in a conscious and purposeful manner, was provided to the future systems professional!

The three capabilities of the systems professional include the artifact-workfloworganization hierarchy, the theory-practice abyss, and the analysis-design dialectics. They were not enough for the successful intervention of human, industrial and social affairs by means of modern ICT-artifacts. However, they did contribute significantly to a mastery of the real-life complexity in a manner that the systems professional would like to possess! 


\subsection{Lecturing Perspective}

Working together in the course teams, with academic teachers at different levels, was a positive experience for all involved - students and teachers alike. The students became less dependent on one or a few teachers, which provided better student access to the right competence for student-teacher dialogue and discussion.

After some initial difficulties, the teachers also found working in a group more stimulating than working in isolation. A course team together with the students also became more like a normal working group in industry and less like an artificial educational composition.

We also found that the introduction of new teachers became much easier to handle than before. Changes in faculty staff were also easier since the senior member of a course team tutored assistant teachers and newly engaged teachers. Course material such as assignments, laboratory lessons, instructions, and different kind of practices, were also handed over to the new staff member of a team; in that sense, no one "owned" their teaching material; it was the property of a course team. In summary, the most positive outcome from the teamwork included:

o limiting students' and other faculty members' dependencies on a particular staff member;

○ high student access to teachers with the relevant competence;

o increased quality and continuous improvements as part of the course team work;

○ a well-functioning teacher-tutor system;

$\mathrm{O}$ an increase of student and teacher democracy in planning and decision-making.

\subsection{The Researcher Perspective}

The Östersund program created good potential for an academic career and provided a solid foundation for work as a researcher. Indeed, several former students are now either full or associate professors at various universities and in various disciplines.

The strong focus on methodology provided by the Östersund program prepared students for a professional research career. There were also several opportunities for the students to practice research already during their studies, for example, when writing the thesis. The objectives required of the students were high: to present the thesis work at international conferences and then to submit it for publication in academic journals - challenging goals which several students did indeed accomplish. This also exposed the students to what it means to be a researcher.

A second key feature of the Östersund program that was beneficial for a future career in research was its multi-disciplinary focus. This included a variety of subjects starting with mathematics, statistics, and computer sciences, proceeding with economics, business and management sciences, then to psychology, sociology, political sciences and the law, and to various philosophical domains, which together with the coordination of the Systems Sciences aimed at a holistic comprehension of the Information Systems thinking and practice.

A third key feature of a more practical nature was the opportunity offered to the students to participate in ongoing research projects conducted by senior staff members at the department, all of which prepared students for research work. 


\subsection{The Doctoral Candidate Perspective}

To what degree did the program prepare students for the exciting work as doctoral candidates? According to an old Swedish proverb, practice gives skills. From that point of view, the Östersund program prepared a doctoral candidate for an eventual academic career in the following ways.

The formulation of relevant research questions and research problems is an important part of the doctoral research process. In the pedagogical model of the Östersund program, the undergraduate students became responsible for their own learning process. At the end of the program, students also had to formulate questions for their bachelor and master thesis work. Those core elements of the program have provided a good foundation for the ability to formulate questions and research problems.

Communicating with different stakeholders is another ability that is typically needed for a doctoral candidate. The Östersund program included several training opportunities in communication, both with companies and with the academic world. There was the obligatory writing of the bachelor thesis and then the master's thesis; the latter in a research paper format, for example.

The Östersund program had a methodology focus that prepared the undergraduate students for solving problems in a methodical and reflective manner. This provided an important capability for a doctoral research process, partly due to the experience of using different types of methods, but also due to the contribution of new insights that emerged from using different methodological perspectives. All those educational qualities shaped independent and self-motivating students.

\section{A Final Question}

The vision of the Östersund program for information systems development was specified as, "Helping students to master methods and techniques that are not yet invented. In this way, to make students fit to handle future problems that have yet to present themselves..

Retrospectively, and observing the ongoing trends within the information systems development profession, a challenging question had emerged in the minds of the designers of this unique educational program, namely: to what degree is such a vision too idealistic to fit into the modern factory metaphor that currently prevails in our universities? [3]

\section{References}

1. Holmberg, S.C.: A Study Program Design in Retrospect. In: Gasparski, W., Mlicki, M., Banathy, B.H. (eds.) Social Agency, Dilemmas and Educational Praxiology, pp. 291-307. Transaction Publishers, New Brunswick (1996)

2. Langefors, B.: Theoretical Analysis of Information Systems. Studentlitteratur, Lund (1966) 
3. Ivanov, K.: Whither Computers and Systems? In: Bubenko, J., Jansson, C.G., Kollerbaur, A., Ohlin, T., Yngström, L. (eds.) ICT for people, pp. 125-134. DSV, Stockholm University, Stockholm (2006)

4. Samuelson, K.: Informatics and Systems Science. In: Bubenko, J., Jansson, C.G., Kollerbaur, A., Ohlin, T., Yngström, L. (eds.) ICT for people, pp. 195-200. DSV, Stockholm University, Stockholm (2006)

5. Espejo, R., Schwaninger, M.: Organisational Fitness. Campus Verlag, Frankfurt (1993)

6. Ulrich, W.: Critical Heuristics of Social Planning. Wiley, Chichester (1994)

7. Warfield, J.N.: A Science of Generic Design. Intersystems Publications, Salinas (1990)

8. Jackson, M. C.: Systems Approaches to Management. Kluwer, Plenum, New York (2000)

9. Checkland, P.B.: Systems Thinking, Systems Practice. Wiley, Chichester (1981)

10. van Gigch, J.P.: System Design Modeling and Metamodeling. Plenum, New York (1991)

11. Sommerville, I.: Software Engineering. Addison-Wesley, New York (1989)

12. Wirth, N., Gutknecht, J.: Project Oberon. Addison-Wesley, New York (1992)

13. IEEE Computer Society, http: / / www . computer . org (accessed June 10, 2010)

14. Association for Computing Machinery, http://www.acm.org (accessed June 10, 2010)

15. Simon, H.A.: The Science of the Artificial. MIT Press, Cambridge (1969)

16. Ackoff, L.R., Magidson, J., Addison, H.J.: Idealized Design. Wharton, Upper Saddle River (2006)

17. Banathy, B.H.: Designing Social Systems in a Changing World. Plenum, New York (1996)

18. ACM: IS 2010 Curriculum Guidelines for Undergraduate Degree Programs in Information Systems,

http: / /www.acm.org/education/curricula / IS\%2 $02010 \% 20 \mathrm{ACM} \% 20 \mathrm{fin}$ al.paf (accessed June 10, 2010)

19. Beer, S.: Brain of the Firm. Wiley, Chichester (1981)

20. Popper, K.R.: Objective Knowledge, An Evolutionary Approach, revised edn. Oxford University Press, Oxford (1979)

21. Boulding, K.E.: General Systems Theory-The Skeleton of Science. Management Science 2, 197-206 (1956)

22. Schön, D.A.: Educating the Reflective Practitioner. Toward a New Design for Teaching and Learning in the Professions. Jossey-Bass, San Fransisco (1987)

23. deBono, E.: http://www.edwdebono.com/index.html (accessed March 1, 2010)

24. Miller, J.G.: Living systems. McGraw-Hill, New York (1978)

25. Ackoff, R.L.: Education. In: ibid (ed.) Ackoff's Best, pp. 147-167. Wiley, NY (1999) 